\title{
The Analysis of Pedestrian's Facility Level of Service at Pondok Cina Rail Station's Platform using PTV Viswalk
}

\author{
Exa Heydemans ${ }^{1}$, R. Jachrizal Sumabrata ${ }^{1}$ \\ ${ }^{1}$ University of Indonesia, Civil Engineering Department, 16424 Depok, Indonesia
}

\begin{abstract}
The public's enthusiasm for commuter lane (light train) in Jakarta is now quite high with the addition of the number of passengers every year. Along with the addition of the number of passengers, train stations must also be able to accommodate the number of passengers. Therefore, the authors conducted a study to determine the feasibility of the platform in Station Pondok Cina for accommodating the addition of the number of passengers, in this case pedestrian's level of service is a feasibility parameter of the station. The study was conducted by comparing the existing condition of St. Pondok Cina's platform with the future condition in coming years. Existing condition is learned by survey in the field and then processed manually for determining the pedestrian's level of service. The future condition is made in simulating model and processed by PTV Viswalk to get an overview in the coming years. Model parameters are estimated based on existing condition parameters and passenger targets. The results of this study show the existing station design will not be able to accommodate the number of passenger plans. Level of service Station Pondok Cina is bad enough and will not be able to accommodate the additional number of passengers later, therefore the design of the plan station needs to be realized to meet the demand of passengers so the pedestrian's level of service, which are influenced by the size of the pedestrian area and the number of incoming access, can be preferable.
\end{abstract}

\section{Introduction}

The public's enthusiasm for commuter lane (light train) in Jakarta is now quite high with the addition of the number of passengers every year. Along with the increases of public's enthusiasm, government apprehend this situation is proper opportunity for establishing public transportation as main transportation in Jakarta. The government has set high target for public transport, and PT. KAI as National Institution is responsible for commuter lane, which includes light train and the station for boarding and alighting the passengers.

Light train station Pondok Cina (in Depok) is one of PT.KAI's program for complying their target, which is 1.2 million passengers per day in 2019. This area is a potential area for developing transit area (Transit Oriented Development), so PT. KAI and PT. Perumnas (National Institution) is building transit-oriented development area in Pondok Cina, with light train station as a central. Area around station will be compact area for pedestrian as TOD criteria and an apartment will be built onto light train station. It will trigger the pedestrian for taking public transportation (Carvero, 2007)[1](Ya-Ting Peng, 2017)[2], which is commuter lane, because it is more convenient and closer than before.

The increases of pedestrian in Pondok Cina will increase the passenger of commuter lane, so there will be more load in light train and the station. The capacity of light train and station are crucial aspect for fulfilling target. Along with the significant change that government planned, come up question whether the plan meets the expectations or not, how feasible the plan for fulfilling the target is, how station and light train meets the passengers target, and etcetera. This research is expected for answering the question above, in another way the objective of this research is analyze the level of service on station's platform.

Analyzing the level of service on station's platform will help us for designing the detail of station for fulfilling target and predicting how the situation in 2019 is. This research simulated the recent condition and situation of station's platform and the future condition and situation in 2019, using PTV Viswalk as simulator and program analyst for pedestrian level of service. This research has been done for understanding the situation of station in 2018 and 2019, so the plan will not be wasted because the situation of station has been predicted and will not causing design problem in future.

\subsection{Objective}

The study aims to analyze the level of service of pedestrian facility at Pondok Cina station's platform currently and in 2019. 


\section{Level of Service}

The level of service (LOS) is a parameter in transportation for measuring the quality of transportation's facility, as for pedestrian or vehicle traffic. There are various example of LOS, but the most influential is proposed by Fruin[3] and integrated to Highway Capacity Manual (HCM)[4]. Generally, level of service is broken down to six levels. This study uses HCM level of service as reference for analyzing the station's platform.

Table 1. Pedestrian Level of Service Walkways HCM

\begin{tabular}{|c|c|c|}
\hline $\begin{array}{c}\text { Level of Service } \\
\text { (LOS) }\end{array}$ & Space Modulus & Pedestrian Flow \\
\hline LOS A & $>5.6 \mathrm{~m}^{2} / p$ & $\leq 16 p / \mathrm{min} / \mathrm{m}$ \\
\hline LOS B & $3.7-5.6 \mathrm{~m}^{2} / p$ & $16-23 p / \mathrm{min} / \mathrm{m}$ \\
\hline LOS C & $2.2-3.7 \mathrm{~m}^{2} / p$ & $23-33 p / \mathrm{min} / \mathrm{m}$ \\
\hline LOS D & $1.4-2.2 \mathrm{~m}^{2} / p$ & $33-49 p / \mathrm{min} / \mathrm{m}$ \\
\hline LOS E & $0.75-1.4 \mathrm{~m}^{2} / p$ & $49-75 p / \mathrm{min} / \mathrm{m}$ \\
\hline LOS F & $<0.75 \mathrm{~m}^{2} / p$ & varies $p / \mathrm{min} / \mathrm{m}$ \\
\hline
\end{tabular}

Table 2. Pedestrian Level of Service Queueing HCM

\begin{tabular}{|c|c|}
\hline $\begin{array}{c}\text { Level of Service } \\
\text { (LOS) }\end{array}$ & Space Modulus \\
\hline LOS A & $>1.2 \mathrm{~m}^{2} / p$ \\
\hline LOS B & $0.9-1.2 \mathrm{~m}^{2} / p$ \\
\hline LOS C & $0.6-0.9 \mathrm{~m}^{2} / p$ \\
\hline LOS D & $0.3-0.6 \mathrm{~m}^{2} / p$ \\
\hline LOS E & $0.2-0.3 \mathrm{~m}^{2} / p$ \\
\hline LOS F & $<0.2 \mathrm{~m}^{2} / p$ \\
\hline
\end{tabular}

The level of service standard that has been used is adjusted by pedestrian activities. There are three primary activities of pedestrian in station, those are walking, queueing, and ascending or descending stair. Each activity is parameterized based on their own standard of LOS, which shows by table 1 and table 2 .

\section{Methodology}

Methods for analyzing the level of service of pedestrian's facility on station platform include these three general methods (Yoongho, 2016)[5] (i) survey or data retrieval of station's layout and pedestrian traffic, (ii) Estimation of future pedestrian traffic in station, and (iii) evaluation of pedestrian's facility level of service, that use PTV Viswalk for simulating model.

\subsection{Data Retrieval and Survey}

The survey on layout of station is done by manually observe on the field (station). The layout has been drawn according to the exact measurement of the station. This existing layout is used for creating model that represent existing station. The future layout is obtained by collecting data from PT. KAI and PT. Perumnas, that is used for modelling the future station. The data retrieval of pedestrian traffic is done by manually counting the pedestrian flow and density in certain spots. The result is used for modelling the condition and situation of pedestrian in existing model simulation. The data that has been used is the data that show maximum traffic in a day, which is the traffic in $06.15-07.15 \mathrm{am}$.

\subsection{Estimation of Future Pedestrian Traffic}

Comparison method is done for estimating the pedestrian traffic in 2019. It is compared the target passenger in 2019 by PT. KAI with the passengers in station presently. The result of comparison is the estimate pedestrian flow in 2019, in and out of station.

$$
\text { Future Pedestrian Flow }=(a \div b) \times \mathrm{c}
$$

Which $a$ represents PT. KAI passenger target in 2019, it is 1.2 million passangers; $b$ represents total passenger Jakarta in 2017 , it is 865,238 passangers ; $c$ is pedestrian flow Pondok Cina station, it is 3119 passangers per hour.

Use equation (1), the future pedestrian flow is obtained 4326 pedestrian per hour.

\subsection{Simulation}

The Evaluation of pedestrian's facility level of service used model simulation as evaluator, PTV Viswalk is used for creating and running the simulation model. For evaluation level of service, HCM is used as model parameter for showing how the level of service is. The model of simulation is created various type of model that represent various condition and situation of pedestrian traffic in station's platform. The models represent the existing condition of station, that use the data of existing station's layout and present pedestrian traffic, and various future condition of station, that use estimate pedestrian traffic and future layout of station.

\subsubsection{Model 1: Existing Layout and Existing Pedestrian Traffic}

Model 1 of simulation made based on observed condition and situation of current station. The simulation analyzed based on pedestrian density or space modulus that happened at various area and stairs/ramp that happened on walkways and queueing condition. Model 1design is showed by figure 1 . 


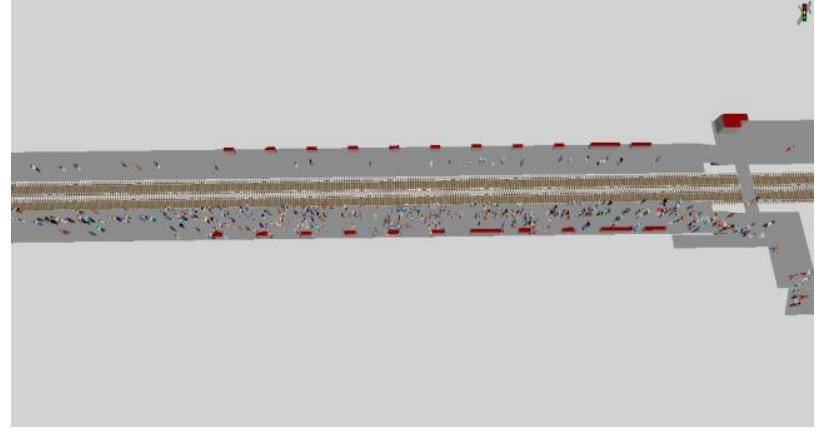

Fig. 1. Model 1 Design Simulation

\subsubsection{Model 2: Future Layout \#1 and Future Pedestrian Traffic}

Model 2 is made based on future layout of Pondok Cina station that has two accesses each platform and wider platform about $61 \%$ than existing layout. The access has one function for entering or exiting the platform. The tap gate of station is located upstairs of the platform. The future design of station layout accommodates pedestrian traffic in 2019 that has flow about $4326 \mathrm{p} / \mathrm{h}$, this flow is greater than existing flow about $39 \%$. Model 2 Design is showed by figure 2 and figure 3 .

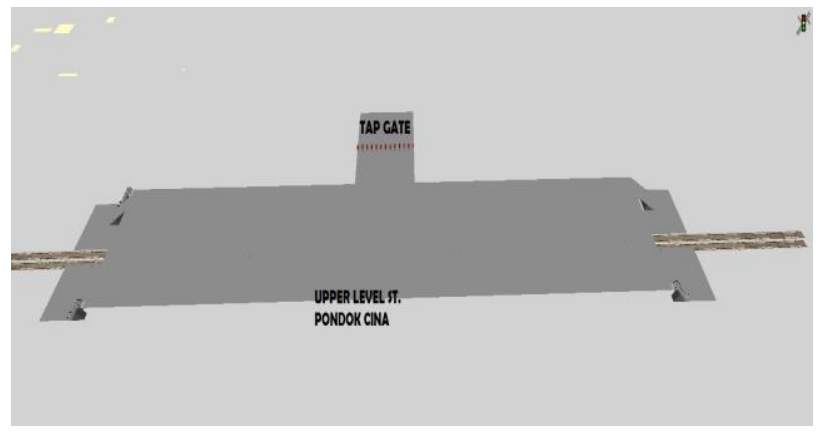

Fig. 2. Model 2 Top View Design Simulation

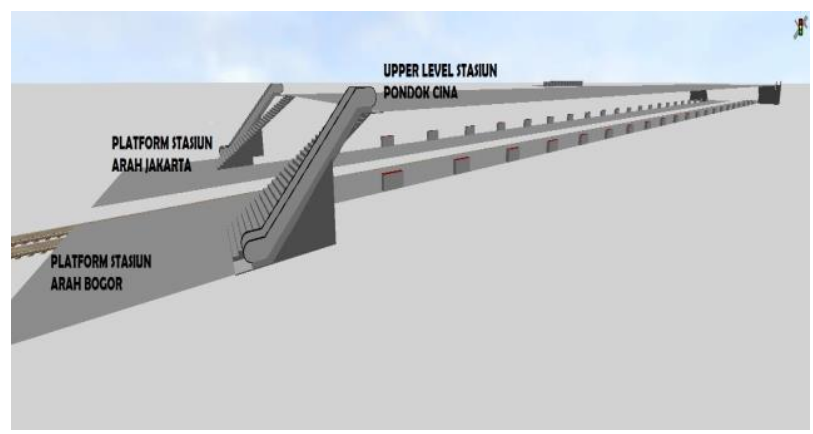

Fig. 3. Model 2 Side View Design Simulation

\subsubsection{Model 3: Future Layout \#2 and Future Pedestrian Traffic}

The future layout \#2 of station's platform in Model 3 has four accesses for entering and exiting each platform and has exactly same wide with model 2. Model 3 accommodates 2019 pedestrian traffic, which is 4326 p/hour. Model 3 design is showed by figure 4 , figure 5 and figure 6.

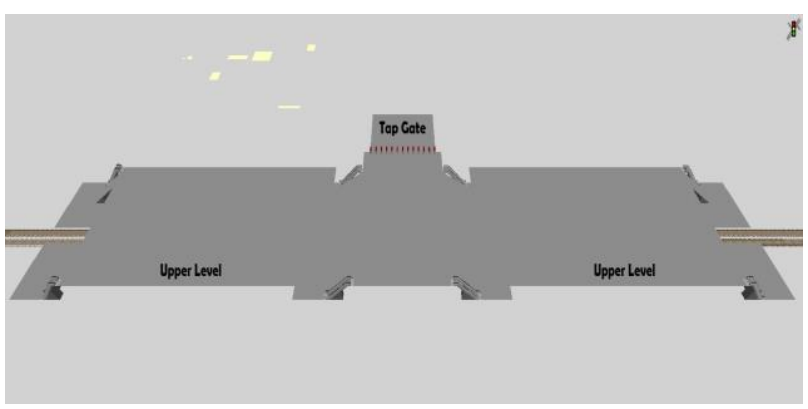

Fig. 4. Model 3 Top View Design Simulation

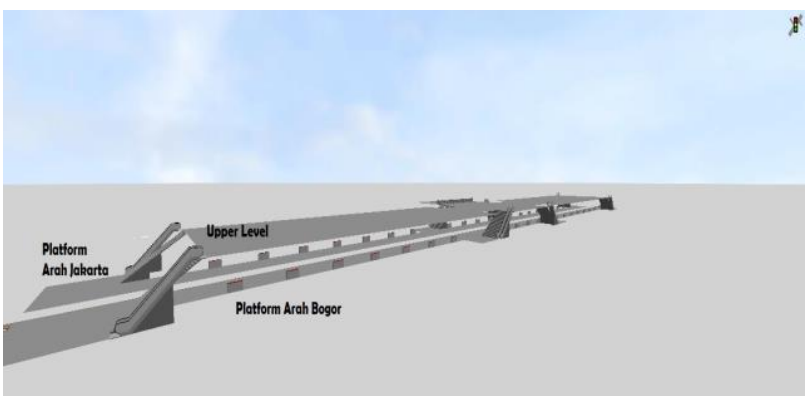

Fig. 5. Model 3 Side View \#1 Design Simulation

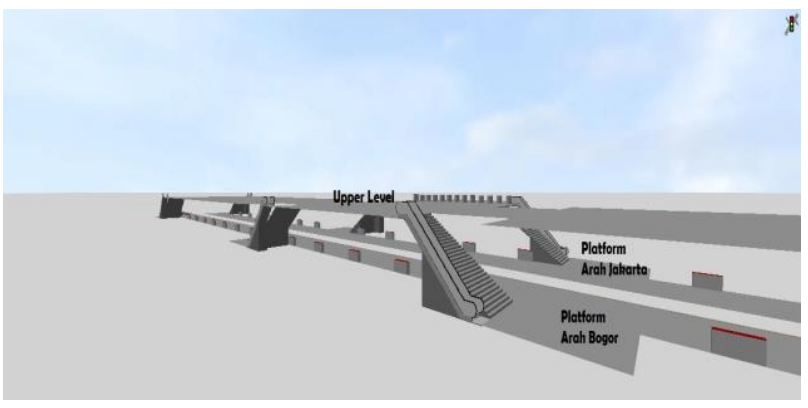

Fig. 6. Model 3 Side View \#2 Design Simulation

\subsubsection{Model Validation}

In this process, the retrieval data of pedestrian density that has been observed compared to the result of pedestrian's density in simulation model 1 (Robert, 2011)[6]. This process is done for validating the models.

Table 3 shows that there is quite difference density in area $\mathrm{A}$ of observed result and area measurement 3 of model 1. The difference is about $99.35 \%$ and this comparison is showing that the real situation and model is quite different or the model in area measurement 3 does not represent the situation at area $\mathrm{A}$ in real situation. This matter happens because there is actually different condition in this area, which is the area A of actual situation includes the passengers for boarding the woman-only carriage of the train, so women passenger tends to wait in this area. The train in model 1 does not distinguish the carriage's requirement, so there is no tendency for women passenger waiting in particular area in model. 
The other comparison area show the difference is about $25 \%$, and the farthest area from the area $\mathrm{A}$ is $4.23 \%$.

Table 3. Pedestrian Density Comparison between Observation Result and Model 1 Result

\begin{tabular}{|c|c|c|c|c|c|c|c|}
\hline \multicolumn{3}{|c|}{ Model 1 } & \multicolumn{2}{c|}{ Comparison } & \multicolumn{3}{c|}{ Observation Result } \\
\hline $\begin{array}{c}\text { Area } \\
\text { Measurement }\end{array}$ & DensMax & $\begin{array}{c}\text { Space } \\
\text { Modulus }\end{array}$ & $\begin{array}{c}\mathrm{M} \\
\text { Difference } \\
\left(\mathrm{m}^{2} 2 / \mathrm{p}\right)\end{array}$ & $\begin{array}{c}\mathrm{M} \\
\text { Difference } \\
(\%)\end{array}$ & $\begin{array}{c}\text { Observed } \\
\text { Area }\end{array}$ & Density & $\begin{array}{c}\text { Space } \\
\text { Modulus }\end{array}$ \\
\hline 3 & 4,395623 & 0,2275 & 0,113381 & 99,35483 & Area A & 8,7629 & 0,11412 \\
\hline 4 & 4,228171 & 0,23651 & $-0,06981$ & 22,7892 & Area B & 3,2646 & 0,30632 \\
\hline 5 & 2,302469 & 0,43432 & 0,091963 & 26,86217 & Area C & 2,921 & 0,34235 \\
\hline 6 & 1,883838 & 0,53083 & $-0,02345$ & 4,231483 & Area D & 1,8041 & 0,55429 \\
\hline
\end{tabular}

\section{Result}

After getting done with data retrieval and survey, the data that has been obtained and the model that has been designed is processed and brought out the result.

\subsection{Observed Condition and Situation of Station}

The pedestrian flow that has been surveyed for entering the platform from two tap gates of station are 2867 pedestrian (Tap Gate Pondok Cina) and 252 pedestrians (Tap Gate UI). The amount of pedestrian flow shows the level of service based on the pedestrian flow parameter is level of service (LOS) E about $49-75 \mathrm{p} / \mathrm{min} / \mathrm{m}$, the exact value is $51.9833 \mathrm{p} / \mathrm{min} / \mathrm{m}$.

The level of service based on space modulus that happened in queueing condition shows in table 4 at various space that has been surveyed.

Table 4. Pedestrian LOS Queueing Result of Observation Based on Space Modulus

\begin{tabular}{|c|c|c|c|c|}
\hline \multicolumn{3}{|c|}{ LOS Queueing Based on Space Modulus } \\
\hline \multirow{2}{*}{$\begin{array}{c}\text { Observed } \\
\text { Area }\end{array}$} & Density & $\begin{array}{c}\text { Space } \\
\text { Modulus }\end{array}$ & \multicolumn{2}{c|}{ LOS } \\
\cline { 3 - 5 } & $\mathrm{p} / \mathrm{m}^{\wedge} 2$ & $\mathrm{~m}^{\wedge} 2 / \mathrm{p}$ & $\mathrm{m}^{\wedge} 2 / \mathrm{p}$ & \\
\hline Area A & 8.763 & 0.114 & $<0.2$ & LOS F \\
\hline Area B & 3.265 & 0.306 & $0.3-0.6$ & LOS D \\
\hline Area C & 2.921 & 0.342 & $0.3-0.6$ & LOS D \\
\hline Area D & 1.804 & 0.554 & $0.3-0.6$ & LOS D \\
\hline
\end{tabular}

Table 4 shows the worst level of service happened at Area A, it is $\operatorname{LOS~F~}(<0.2 \mathrm{~m} 2 / \mathrm{p})$, the exact value is 0.114 $\mathrm{m} 2 / \mathrm{p}$. The other area that has been surveyed shows LOS $\mathrm{D}(0.3-0.6 \mathrm{~m} 2 / \mathrm{p})$. Area A has worst level of service because Area $\mathrm{A}$ is the closest area in platform to the entrance/exit. The value of space modulus is higher if that area is closer to the entrance/exit.

\subsection{Model 1 Simulation Result}

Model 1 is simulated and obtained the result that shows the level of service, which is showed by figure 7 and figure 8 .

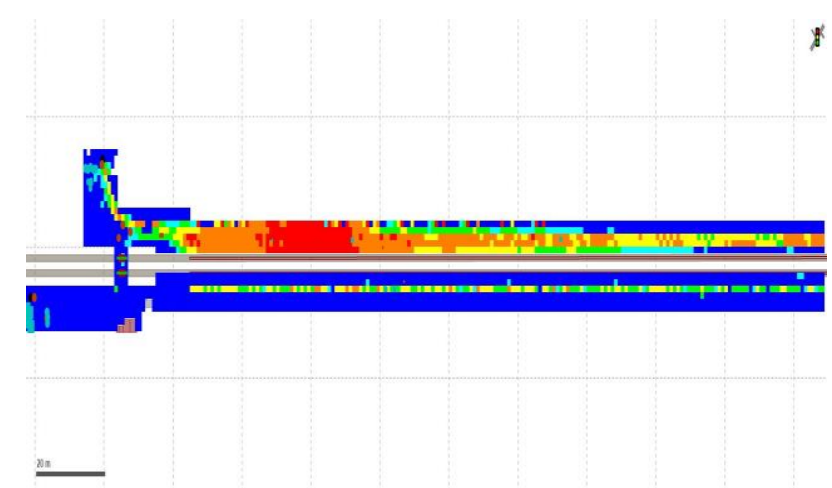

Fig. 7. LOS Walkways Density Average Model 1

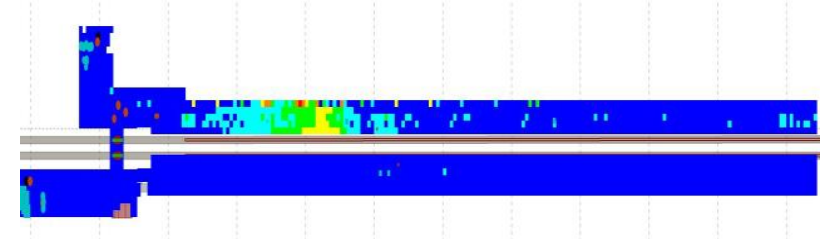

Fig. 8. LOS Queueing Density Average Model 1

Figure 8 and figure 9 shows the level of service area near entrance/exit in east platform is quite high; and declining to far-way side of entrance/exit in platform.

Table 5. Simulation Value of LOS Walkways and Queueing Based on Space Modulus Model 1

\begin{tabular}{|c|c|c|c|c|c|c|c|c|}
\hline \multicolumn{9}{|c|}{ LOS Density Model 1} \\
\hline \multirow{3}{*}{ SimRun } & \multirow{3}{*}{ Time Int } & \multirow{3}{*}{$\begin{array}{c}\text { Area } \\
\text { Measurement }\end{array}$} & \multirow{3}{*}{$\begin{array}{l}\text { Dens } \\
\text { Max }\end{array}$} & \multirow{3}{*}{\begin{tabular}{|c|}
$\begin{array}{c}\text { Space } \\
\text { Modulus }\end{array}$ \\
$\mathrm{m}^{\wedge} 2 / \mathrm{p}$ \\
\end{tabular}} & \multicolumn{2}{|c|}{ LOS Walkways } & \multicolumn{2}{|c|}{ LOS Queueing } \\
\hline & & & & & \begin{tabular}{|l|} 
Range \\
\end{tabular} & Resul & Range & Result \\
\hline & & & & & $\mathrm{m}^{\wedge} 2 / \mathrm{p}$ & Nesum & $\mathrm{m}^{\wedge} 2 / \mathrm{p}$ & Nesuit \\
\hline Max & $2700-3600$ & 1 & 3,886 & 0,2573 & $<0.75$ & LOS F & $0.2-0.3$ & LOS E \\
\hline Max & $2700-3600$ & 2 & 4,217 & 0,2371 & $<0.75$ & LOS F & $0.2-0.3$ & LOS E \\
\hline Max & $2700-3600$ & 3 & 4,396 & 0,2275 & $<0.75$ & LOSF & $0.2-0.3$ & LOS E \\
\hline Max & $2700-3600$ & 4 & 4,228 & 0,2365 & $<0.75$ & LOS F & $0.2-0.3$ & LOS E \\
\hline Max & $1800-2700$ & 5 & 2,302 & 0,4343 & $<0.75$ & LOS F & $0.3-0.6$ & LOS D \\
\hline Max & $2700-3600$ & 6 & 1,884 & 0,5308 & $<0.75$ & LOSF & $0.3-0.6$ & LOS D \\
\hline
\end{tabular}

The area measurement 1 is area in front of east tap gate and area measurement 2 is a crossing area from west side of station to east side of station. This station is not surveyed because it is not located on platform. Area measurement 3 to 6 represent observed area A to D respectively. According to table 5, the value of LOS in area measurement 3 to 6 of simulation show the same pattern that observed areas have.

In ramps and stairs, the highest level of service located in stair of east platform, which is LOS F as shown in table 6. The stair and ramp of east platform have quite high value of space modulus because of the east platform has high pedestrian flow. 
Table 6. Simulation Value of LOS in Stair and Ramp Model 1

\begin{tabular}{|c|c|c|c|c|c|c|c|c|}
\hline \multicolumn{9}{|c|}{ LOS Density in Ramp \& Stair Model 1} \\
\hline \multirow{3}{*}{ SimRun } & \multirow{2}{*}{ TimeInt } & \multirow{3}{*}{$\begin{array}{c}\text { Ramp } \\
\& \\
\text { Stairs }\end{array}$} & \multirow{3}{*}{$\begin{array}{l}\text { Density } \\
\mathrm{p} / \mathrm{m}^{\wedge} 2\end{array}$} & \multirow{3}{*}{$\begin{array}{c}\text { Space } \\
\text { Modulus } \\
\mathrm{m}^{\wedge} 2 / \mathrm{p}\end{array}$} & \multicolumn{2}{|c|}{ LOS Walkways } & \multicolumn{2}{|c|}{ LOS Queueing } \\
\hline & & & & & \multirow{2}{*}{$\begin{array}{l}\text { Range } \\
m^{\wedge} 2 / p\end{array}$} & \multirow{2}{*}{ Result } & Range & \multirow{2}{*}{ Result } \\
\hline & Seconds-to & & & & & & $\mathrm{m}^{\wedge} 2 / \mathrm{p}$ & \\
\hline $\mathrm{M}$ & $1800-2700$ & 1 & & 2,8399 & & 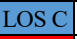 & $>1.2$ & 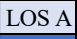 \\
\hline Max & 1800 & 2 & & 23 & & LOS F & $0.6-0.9$ & LOS C \\
\hline Max & 1800 & 3 & 4 & 26 & 6 & LOS A & .2 & LOS A \\
\hline Max & $1800-2700$ & 4 & 0,085 & 11,72 & $>5.6$ & LOS A & $>1.2$ & LOS A \\
\hline
\end{tabular}

\subsection{Model 2 Simulation Result}

Model 2 is simulated and obtained result that shows the level of service, which is showed by figure 9, figure 10 , figure 11 and figure 12.

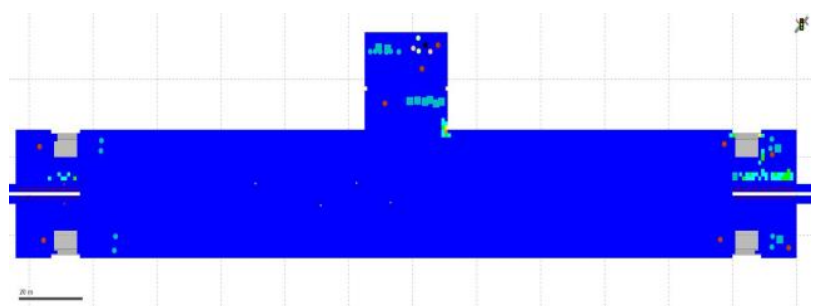

Fig. 9. LOS Queueing Density Average Upper Level Model 2.

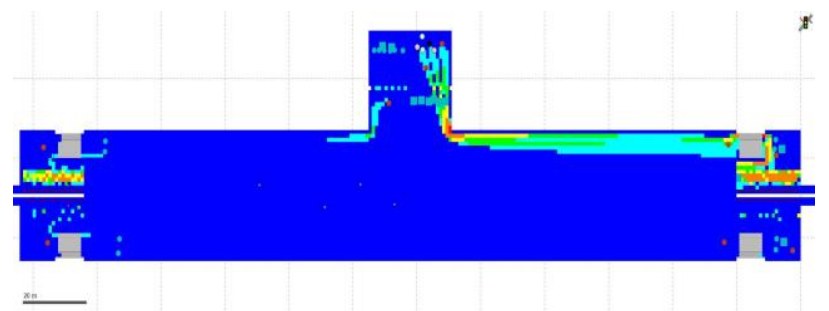

Fig. 10. LOS Walkways Density Average Upper Level Model 2

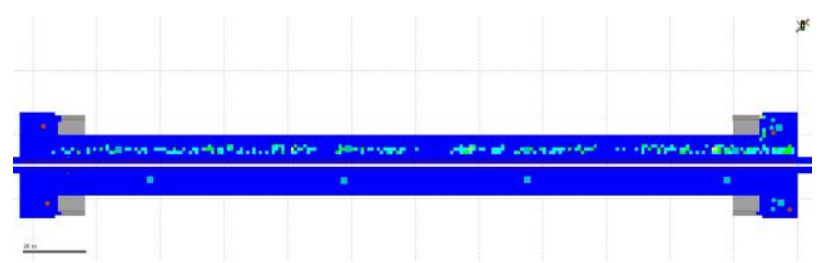

Fig. 11. LOS Queueing Density Average Platform Model 2

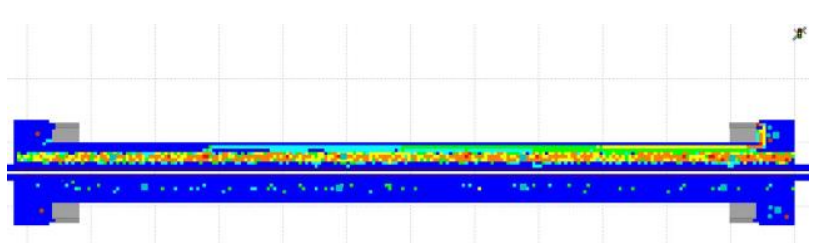

Fig. 12. LOS Walkways Density Average Platform Model 2

Figure 9 and figure 10 show the upper level of station is not having high pedestrian density, but in entrance side area to platform, there is quite high level of service. The simulation value of model 2 is showed by table 7 and table 8 .

Area measurement $1-11$ based on table 7 is located on platform and area measurement 12 is located near tap gate in upper level of station. Table 7 shows the level of service in platform is spread evenly, but the area near the entrance has quite poor level of service, which is area measurement 8,9 and 10 . Table 8 shows the result of level of service in stair and escalator is a decent result (LOS A), but the stairs in east platform that used by pedestrian to enter the platform has LOS C.

Table 7. Simulation Value of LOS Based on Space Modulus Model 2

\begin{tabular}{|c|c|c|c|c|c|c|c|c|}
\hline \multicolumn{9}{|c|}{ LOS Density Model 2} \\
\hline \multirow{3}{*}{ SimRun } & \multirow{2}{*}{ Time Int } & \multirow{3}{*}{$\begin{array}{c}\text { Area } \\
\text { Measurement }\end{array}$} & \multirow{3}{*}{\begin{tabular}{|c|}
$\begin{array}{c}\text { Dens } \\
\text { Max }\end{array}$ \\
$\mathrm{p} / \mathrm{m}^{\wedge} 2$ \\
\end{tabular}} & \multirow{3}{*}{\begin{tabular}{|c|} 
Space \\
Modulus \\
$\mathrm{m}^{\wedge} 2 / \mathrm{p}$ \\
\end{tabular}} & \multicolumn{2}{|c|}{ LOS Walkways } & \multicolumn{2}{|c|}{\begin{tabular}{|l} 
LOS Queueing \\
\end{tabular}} \\
\hline & & & & & Range & & Range & \\
\hline & Second to- & & & & $\mathrm{m}^{\wedge} 2 / \mathrm{p}$ & Kes & $m^{\wedge} 2 / p$ & Kesuit \\
\hline Max & $2700-3600$ & 1 & 1,09 & 0,9163 & $0.75-1.4$ & LOS E & $0.9-1.2$ & LOS B \\
\hline Max & $2700-3600$ & 2 & 1,39 & 0,7189 & $<0.75$ & LOS F & $0.6-0.9$ & LOSC \\
\hline Max & $1800-2700$ & 3 & 1,36 & 0,7368 & $<0.75$ & LOS F & $0.6-0.9$ & LOS C \\
\hline $\operatorname{Max}$ & $2700-3600$ & 4 & 1,59 & 0,6271 & $<0.75$ & LOSF & $0.6-0.9$ & LOS C \\
\hline $\operatorname{Max}$ & $2700-3600$ & 5 & 1,43 & \begin{tabular}{|l|}
0,7017 \\
\end{tabular} & $<0.75$ & LOS F & $0.6-0.9$ & LOS C \\
\hline Max & $2700-3600$ & 6 & 1,59 & 0,6271 & $<0.75$ & LOS F & $0.6-0.9$ & LOS C \\
\hline $\operatorname{Max}$ & $2700-3600$ & 7 & 1,29 & 0,7756 & $0.75-1.4$ & LOS E & $0.6-0.9$ & LOS C \\
\hline Max & $2700-3600$ & 8 & 1,73 & 0,5779 & $<0.75$ & LOS F & $0.3-0.6$ & LOS D \\
\hline Max & $2700-3600$ & 9 & 2,28 & 0,4393 & $<0.75$ & LOS F & $0.3-0.6$ & LOS D \\
\hline Max & $2700-3600$ & 10 & 1,77 & 0,5665 & $<0.75$ & LOS F & $0.3-0.6$ & LOS D \\
\hline Max & $2700-3600$ & 11 & 0,27 & 3,6773 & $3.7-5.6$ & LOS B & $>1.2$ & LOS A \\
\hline Max & $900-1800$ & 12 & 0,16 & 6,0807 & $>5.6$ & LOS A & $>1.2$ & LOS A \\
\hline
\end{tabular}

Table 8. Simulation Value of LOS in Stair and Escalator Model 2

\begin{tabular}{|c|c|c|c|c|c|c|c|c|}
\hline \multicolumn{9}{|c|}{ LOS Density in Ramp and Escalator Model 2} \\
\hline \multirow{3}{*}{ SimRun } & \multirow{2}{*}{ TimeInt } & \multirow{3}{*}{$\begin{array}{c}\text { Ramp } \\
\& \\
\text { Stairs }\end{array}$} & \multirow{2}{*}{ Density } & \multirow{2}{*}{$\begin{array}{c}\text { Space } \\
\text { Modulus }\end{array}$} & \multicolumn{2}{|c|}{ LOS Walkways } & \multicolumn{2}{|c|}{ LOS Queueing } \\
\hline & & & & & Range & Resu & Range & Res \\
\hline & Second to- & & $\mathrm{p} / \mathrm{m}^{\wedge} 2$ & $m^{\wedge} 2 / p$ & $m^{\wedge} 2 / p$ & & $m^{\wedge} 2 / p$ & \\
\hline Max & $2700-3600$ & 1 & 0,3468 & 2,8835 & $2.2-3.7$ & LOSC & $>1.2$ & LOS A \\
\hline $\operatorname{Max}$ & 2700 & 2 & & & $>5$ & LOS A & & \\
\hline $\mathrm{M}$ & 180( & 3 & & & 3.7 & $\overline{\mathrm{LO}}$ & & \\
\hline $\mathrm{M}$ & 90 & 4 & & & & & & \\
\hline Max & 900 & 5 & & & & & & ILC \\
\hline $\mathrm{M}$ & 180 & 6 & & & $>5.6$ & LOS A & $>1.2$ & LOS A \\
\hline Max & $900-$ & 7 & 099 & 0,7634 & $0.75-$ & LOS E & $0.6-0.9$ & LOS C \\
\hline Max & $900-1800$ & 8 & 0,1612 & 6,205 & $>5.6$ & LOS A & $>1.2$ & LOS A \\
\hline
\end{tabular}

\subsection{Model 3 Simulation Result}

Model 3 is simulated and obtained result that shows the level of service, which is showed by figure 13, figure 14 , figure 15 and figure 16.

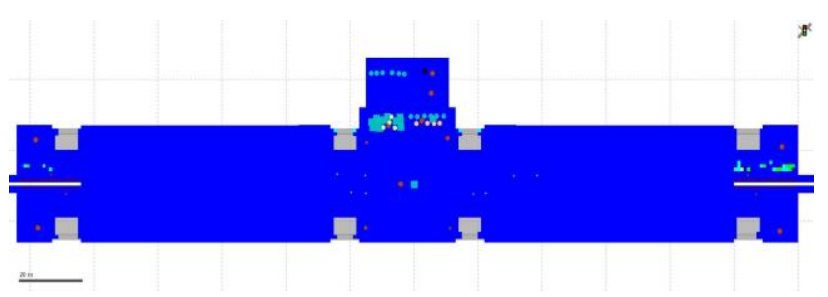

Fig. 13. LOS Queueing Density Average Upper Level Model 3

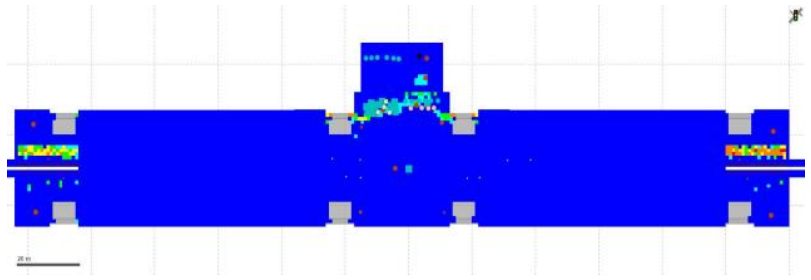

Fig. 14. LOS Walkways Density Average Upper Level Model 3 


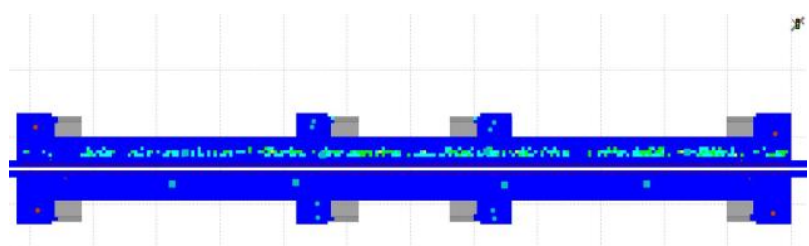

Fig. 15. LOS Queueing Density Average Platform Model 3

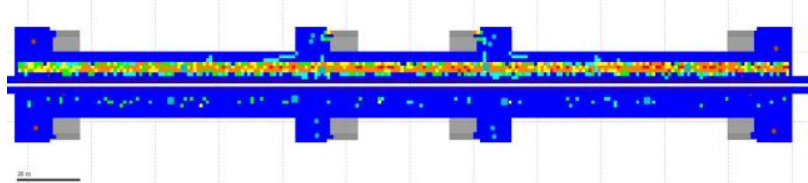

Fig. 16. LOS Walkways Density Average Platform Model 3

Table 9. Simulation Value of LOS Based on Space Modulus Model 3

\begin{tabular}{|c|c|c|c|c|c|c|c|c|}
\hline \multicolumn{9}{|c|}{ LOS Density Model 3} \\
\hline \multirow{3}{*}{ SimRun } & \multirow{3}{*}{ Time Int } & \multirow{3}{*}{$\begin{array}{c}\text { Area } \\
\text { Measurement }\end{array}$} & \multirow{2}{*}{$\begin{array}{c}\text { Dens } \\
\text { Max }\end{array}$} & \multirow{2}{*}{$\begin{array}{c}\text { Space } \\
\text { Modulus }\end{array}$} & \multicolumn{2}{|c|}{ LOS Walkways } & \multicolumn{2}{|c|}{ LOS Queueing } \\
\hline & & & & & Range & & Range & \\
\hline & & & $\mathrm{p} / \mathrm{m}^{\wedge} 2$ & $\mathrm{~m}^{\wedge} 2 / \mathrm{p}$ & $\mathrm{m}^{\wedge} 2 / \mathrm{p}$ & Hestit & $\mathrm{m}^{\wedge} 2 / \mathrm{p}$ & Result \\
\hline Max & $2700-3600$ & 1 & 1,754 & 0,57 & $<0.75$ & OS F & $0.3-0.6$ & LOS D \\
\hline Max & $2700-3600$ & 2 & 1,754 & 0,57 & $<0.75$ & $\mathrm{SF}$ & $0.3-0.6$ & LOS D \\
\hline Max & $2700-3600$ & 3 & 1,413 & 0,708 & $<0.75$ & $\mathrm{~S} 1$ & $0.6-0.9$ & LOS C \\
\hline Max & $2700-3600$ & 4 & 1,72 & 0,5814 & $<0.75$ & $\mathrm{SH}$ & $0.3-0.6$ & LOS D \\
\hline Max & $2700-3600$ & 5 & 1,41 & 0,7091 & $<0.75$ & S 1 & $0.6-0.9$ & LOS C \\
\hline Max & $2700-3600$ & 6 & 1,617 & 0,6185 & $<0.75$ & US & $0.6-0.9$ & LOS C \\
\hline Max & $2700-3600$ & 7 & 1,858 & 0,5384 & $<0.75$ & $\mathrm{OSI}$ & $0.3-0.6$ & LOS D \\
\hline Max & $2700-3600$ & 8 & 1,789 & 0,5591 & $<0.75$ & & $0.3-0.6$ & LOS D \\
\hline Max & $2700-3600$ & 9 & 1,827 & 0,5473 & $<0.75$ & OS F & $0.3-0.6$ & LOS D \\
\hline Max & 900-1800 & 10 & 0,207 & 4,8356 & $3.7-5.6$ & LOS B & $>1.2$ & LOS A \\
\hline Max & 900-1800 & 11 & 0,207 & 4,8251 & $3.7-5.6$ & LOS B & $>1.2$ & LOS A \\
\hline Max & $2700-3600$ & 12 & 0,048 & 20,956 & $>5.6$ & LOS A & $>1.2$ & LOS A \\
\hline Max & $0-900$ & 13 & 0,095 & 10,492 & $>5.6$ & LOS A & $>1.2$ & LOS A \\
\hline Max & $1800-2700$ & 14 & 0,241 & 4,1467 & $3.7-5.6$ & LOS B & $>1.2$ & LOS A \\
\hline
\end{tabular}

Table 10. Simulation Value of LOS in Stair and Escalator Model 3

\begin{tabular}{|c|c|c|c|c|c|c|c|c|}
\hline \multicolumn{9}{|c|}{ LOS Density in Ramp and Escalator Model 3} \\
\hline \multirow{3}{*}{ SimRun } & \multirow{3}{*}{ TimeInt } & \multirow{3}{*}{$\begin{array}{c}\text { Ramp } \\
\& \\
\text { Stairs }\end{array}$} & \multirow{3}{*}{\begin{tabular}{|l|} 
Density \\
$\mathrm{p} / \mathrm{m}^{\wedge} 2$ \\
\end{tabular}} & \multirow{3}{*}{$\begin{array}{c}\text { Space } \\
\text { Modulus } \\
\mathrm{m}^{\wedge} 2 / \mathrm{p} \\
\end{array}$} & \multicolumn{2}{|c|}{ LOS Walkways } & \multicolumn{2}{|c|}{ LOS Queueing } \\
\hline & & & & & \multirow{2}{*}{\begin{tabular}{|l|l|} 
Range \\
$\mathrm{m}^{\wedge} 2 / \mathrm{p}$ \\
\end{tabular}} & \multirow{2}{*}{ Result } & \multirow{2}{*}{\begin{tabular}{|l|} 
Range \\
$\mathrm{m}^{\wedge} 2 / \mathrm{p}$ \\
\end{tabular}} & \multirow{2}{*}{ Result } \\
\hline & & & & & & & & \\
\hline Max & $2700-3600$ & 1 & 0,1814 & 5,5142 & $3.7-5.6$ & LOS B & $>1.2$ & LOS A \\
\hline Max & $2700-3600$ & 2 & & & 5.6 & $\operatorname{LOS} \mathrm{A}$ & $>1.2$ & \\
\hline Max & $0-900$ & 3 & 0,1265 & 7,9071 & $>5.6$ & $\operatorname{LOS} A$ & $>1.2$ & LOS \\
\hline Max & $900-1800$ & 4 & 0,0162 & 61,912 & $>5.6$ & $\operatorname{LOS} \mathrm{A}$ & $>1.2$ & LOS A \\
\hline Max & $1800-2700$ & 5 & 0,0463 & 21,606 & $>5.6$ & $\operatorname{LOS} \mathrm{A}$ & $>1.2$ & LOS A \\
\hline Max & 900-1800 & 6 & 0,0042 & 236,8 & $>5.6$ & $\operatorname{LOS} \mathrm{A}$ & $>1.2$ & LOS A \\
\hline Max & \begin{tabular}{|l|}
$1800-2700$ \\
\end{tabular} & 7 & 0,643 & 1,5551 & $1.4-2.2$ & LOS D & $>1.2$ & LOS A \\
\hline Max & $1800-2700$ & 8 & 0,0663 & 15,087 & $>5.6$ & $\operatorname{LOS} \mathrm{A}$ & $>1.2$ & LOS A \\
\hline Max & $2700-3600$ & 9 & 0,0538 & 18,592 & $>5.6$ & $\operatorname{LOS} A$ & $>1.2$ & LOS \\
\hline Max & 900-1800 & 10 & 0,0046 & 216,5 & $>5.6$ & $\operatorname{LOS} \mathrm{A}$ & $>1.2$ & LOS \\
\hline Max & 900-1800 & 11 & 0,6957 & 1,4373 & $1.4-2.2$ & LOS D & $>1.2$ & LOS A \\
\hline Max & $1800-2700$ & 12 & 0,0699 & 14,298 & $>5.6$ & $\operatorname{LOS} \mathrm{A}$ & $>1.2$ & LOS A \\
\hline Max & $2700-3600$ & 13 & 0,1741 & 5,7437 & $>5.6$ & LOS A & $>1.2$ & LOS A \\
\hline Max & $2700-3600$ & 14 & 0,0349 & 28,673 & $>5.6$ & $\operatorname{LOS} \mathrm{A}$ & $>1.2$ & LOS A \\
\hline Max & 900-1800 & 15 & 0,1306 & 7,6593 & $>5.6$ & $\operatorname{LOS} \mathrm{A}$ & $>1.2$ & LOS \\
\hline Max & $1800-2700$ & 16 & \begin{tabular}{|l|}
0,0276 \\
\end{tabular} & 36,253 & $>5.6$ & $\operatorname{LOS} \mathrm{A}$ & $>1.2$ & LOS A \\
\hline
\end{tabular}

In upper level of station, the pedestrian density is not quite high, so the level of service in upper level shows decent mark as figure 13 and figure 14. The simulation value of model 3 is showed by table 9 and table 10 .

The value of LOS in platform station of model 3 shows diversity, the areas near entrance or exit have worst level of service (LOS D), which is area measurement 1 and 2 those located near exit stair and escalator, area measurement 4 that located near entrance stair and escalator, and area measurement 8 and 9 those located near others exit stair and escalator. The value of level of service in platform is represented by table 9 .

Table 10 represent the simulation value of level of level service in stairs and escalators, which is showing decent result of level of service (LOS A). The level of service is spreading equally in entire stairs and escalators, but there are some escalators that has poor level of service.

\subsection{Comparation Result of LOS in models}

\section{Space Modulus Compartation}

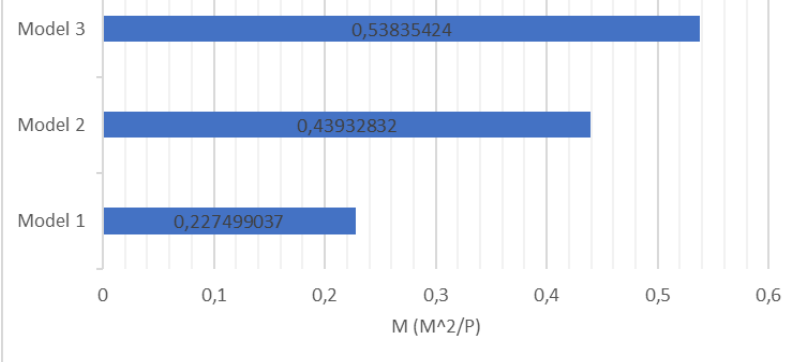

Fig. 17. Graphic of Space Modulus Comparation in Area Measurement of Models

Figure 17 shows the comparation of maximum space modulus in area measurement among models. Model 3 has the greatest value of space modulus, that means the pedestrian in model 3 has the widest room for him/her self than the other two models. Model 1 has the worst value of space modulus.

Model 2 and model 3 have $61 \%$ wider platform than model 1 , so the maximum value of space modulus of model 2 and model is greater than model 1 that has tighter platform.

The access in platform affect the space modulus, it shows model 3 that has four accesses in platform has greater value of space modulus than the other two models. Model 2 has two accesses in platform has greater value of space modulus than model 1 that has only one access in platform.

\section{Conclusion and Future Work}

From the analysis results that have been obtained based on the PTV Viswalk simulation results that have been carried out, it can be concluded that:

(1) The worst level of service among several observation areas on St. Pondok Cina in 2018 is level of service F (LOS F) with a space modulus value of 0.227 
$\mathrm{m} 2 / \mathrm{p}$; Level of service F (LOS F) on ramp with a space modulus of $0.702 \mathrm{~m} 2 / \mathrm{p}$.

(2) The best value of the worst level of service St. Pondok Cina that happened in various scenarios that represent conditions in 2019 is level of service F (LOS F) with a space modulus of $0.538 \mathrm{~m} 2 / \mathrm{p}$; Level of service D (LOS D) on stairs with space modulus value $1.437 \mathrm{~m} 2 / \mathrm{p}$. This scenario has four accesses for entering and exiting the platform, and $2.7 \mathrm{~m}$ wider layout of platform than the existing layout of platform.

From the result of this study after getting the simulation done, it is necessary to recommend that Pondok Cina rail station need platform modification, which is platform addition to $7.1 \mathrm{~m}$ wide and access to platform addition, with minimum 2 accesses because the existing platform of Pondok Cina rail station is not adequate to supply the passengers in 2019. A new design of platform is required with wider platform and have more access to platform.

\section{References}

1. Carvero, R. Transit-oriented development's ridership bonus : a product of self-selection and public policies (2007)

2. Ya-Ting Peng, Zhi-Chun Li, Keechoo Choi. Transitoriented development in an urban rail transportation corridor (2017)

3. Fruin, J.J. Designing for Pedestrian: a level-ofservice concept (1971)

4. Highway Capacity Manual (2000)

5. Yoongho Ahn, Tomoya K., Hiroshi T., Upali V. Estimation of passenger flow for planning and management railway station (2016)

6. Robert, G.S. Verification and validation of simulation models (2011) 